\title{
Building up Systematic Client-Centred Data as a Base for Clinical Outcome within Outpatient Neurorehabilitation
}

\author{
Jessica Vollertsen ${ }^{1,2}$, Kersti Samuelsson ${ }^{3}$ \\ ${ }^{1}$ Department of Rehabilitation and Department of Medical and Health Sciences, Linköping University, \\ Motala, Sweden \\ ${ }^{2}$ Department of Social and Welfare Studies, Linköping University, Norrköping, Sweden \\ ${ }^{3}$ Department of Rehabilitation Medicine and Department of Medicine and Health Sciences, Linköping \\ University, Linköping, Sweden \\ Email: kersti.samuelsson@regionostergotland.se
}

Received 22 December 2015; accepted 22 February 2016; published 25 February 2016

Copyright (C) 2016 by authors and Scientific Research Publishing Inc.

This work is licensed under the Creative Commons Attribution International License (CC BY). http://creativecommons.org/licenses/by/4.0/

(c) (i) Open Access

\begin{abstract}
Objective: This study describes the development and use of a specific database supporting personnel within outpatient neurological rehabilitation to reflect on existing interventions and improve future rehabilitation. Methods: Five outpatient rehabilitation centres in one county council in Sweden were involved in developing and implementing a systematic data collection template within the existing digital medical record system. Data were collected to get more information on the effects of outpatient stroke rehabilitation in patients who received rehabilitation the first year after a stroke (ICD-I64) and patients who received further rehabilitation 1 year or more after a stroke (ICD-I69). Data analysis included evaluation of balance, movement, activity/participation, health-related quality of life, and self-rated health. Results: The ICD-I64 group had positive results after treatment $(p<0.05)$ for all variables and the ICD-I69 group had positive results for balance and activity/participation. Conclusions: The use of systematic data collection provided a platform for employees and managers to discuss and use clinical results to improve the type and quality of rehabilitation interventions.
\end{abstract}

\section{Keywords}

Neurological Rehabilitation, Occupational Therapy, Quality Improvement, Stroke

\section{Introduction}

Through systematic work in clinical settings, occupational therapists together with other rehabilitation profes-

How to cite this paper: Vollertsen, J. and Samuelsson, K. (2016) Building up Systematic Client-Centred Data as a Base for Clinical Outcome within Outpatient Neurorehabilitation. Open Journal of Therapy and Rehabilitation, 4, 10-21. 
sionals strive to find relevant evidence related to their patients' needs. The concept of evidence-based practice (EBP) is well known to occupational therapists and has been implemented and considered to be a natural part of practice in most healthcare professions. EBP has its base in evidence-based medicine (EBM) and both concepts are often used synonymously. EBM was defined in 1996 by Sackett et al. ([1], p. 71]) as "the conscientious, explicit and judicious use of current best evidence in making decisions about the care of individuals"; that is, it is important to combine research with clinical experience and judgment [2]. EBP has been defined as "the systematic interconnecting of scientifically generated evidence with the tacit knowledge of the expert practitioner to achieve a change in a particular practice for the benefit of a well-defined client/patient group” ([3], p. 74]). This means that EBP as a concept also includes the experience and knowledge of rehabilitation professionals in decision making for best clinical practice. Whereas research aims to increase the sum of knowledge and to identify the most effective form of treatment, EBP aims to use evidence to guide clinical interventions and to underpin clinical decision making [4]. However, Sackett et al. [1] argued strongly that EBP was only a part of the clinical decision-making process and that any judgments and decisions were based on a mix of professional expertise and the best available evidence. Evidence should be gathered conscientiously but it should be used judiciously so that the experience of the professionals, the needs of the patient, the demands of the system and the up-to-date evidence are weighted together and so that the best care is given [4]. EBP should ideally also include a systematic follow-up of results, building up local evidence that professionals and managers apply in discussions about different interventions (evidence-based if possible) and whether we as professionals are doing the right things for specific clients or groups of clients.

Stroke is the most common cause of morbidity and long-term disability in Europe, resulting in an enormous economic burden [5]. In Sweden, about 25,000 people a year have a stroke, which is the main cause of neurological impairment [6]. In 2009, the total societal cost for stroke in Sweden was estimated to about $€ 1513$ billion; $21 \%$ of this cost was due to production losses. In addition to acute hospital care, the cost of stroke includes the cost related to reduced quality of life due to resulting disabilities and premature death [7]. People who have had a stroke usually experience problems with occupational performance, participation in society, and quality of life [8] [9], therefore they may need recurrent rehabilitation over a long period of time. The rehabilitation process, including inpatient and outpatient care, is often complex, and thus patients have benefit from interventions given by a multidisciplinary team [10] [11]. Although the amount of evidence for stroke medical care and rehabilitation has increased rapidly over the last 20 years, many questions remain. Acknowledging the gap in understanding, some studies have highlighted the fact that several challenges probably influence how research findings are implemented in clinical practice [11]. However, most reported randomized controlled trials rely on a relatively small sample size, making it difficult to draw general and/or clinical conclusions [12]. Many countries, including Sweden, have developed their own version of recommendations for best practices with respect to stroke care and rehabilitation. These recommendations are based on systematic reviews of the current evidence for specific assessment and interventions. Funded by the state and developed by the National Board of Health and Welfare [13], the Swedish National Guidelines for Stroke Care are similar to the European guidelines, which are also based on EBM, and include a mandate to identify ineffective measurers. Tickle-Degnen and Bedell [14] describe one paradox that is relevant to practitioners in rehabilitation. Practitioners would most certainly make suboptimal decisions if they were to use exclusively the standard levels of evidence models in their selection and use of information. Research has to be combined with clinical experience, sound judgment and a patient perspective. In Sweden there are 89 Quality Registries supported by the state. Most of the registers are developed by physicians and have a clear medical focus [15]. The Swedish government and the Swedish Association of Local Authorities and Regions (SALAR) have done a review of the future development of registries and have pointed out that there is a need to include more health care to support improvements within clinical practice and that there might be a need for new registries, especially within rehabilitation [16].

Within stroke rehabilitation there are two existing Quality Registries; WebRehab [17] and the Swedish stroke register. The aim of WebRehab is to support a high and consistent quality of rehabilitation throughout Sweden and to collect data that can be used for research. The Swedish stroke register focuses on the caring process but lacks some variables for assessing the outcome of inpatient rehabilitation. Some variables on outpatient rehabilitation are included but they are not considered to be informative enough for discussions or decisions on clinical outcome and evidence.

This study describes a systematic data collection process performed in a clinical setting that emphasizes research, professional experience, knowledge, and a client-centred approach. The main objective was to describe 
the development of a specific data template signed to support therapists within outpatient neurology rehabilitation to improve the quality of rehabilitation by following up and discussing outcomes.

\section{Methods}

\subsection{Design and Material}

This was a prospective quasi-experimental clinical study with a before and after design.

Five outpatient rehabilitation centres in one county council in Sweden participated. All centres were engaged in neurology outpatient rehabilitation, and in 2010 they all started to systematically register data to document patient outcome and provide a platform for discussions on future strategies and quality improvement. About 100 employees from various professions (occupational therapists, physiotherapists, physicians, social workers, speech therapists, nurses, and assistant nurses) were involved in building up a customized template to collect data within the existing digital medical record system. Initially, interdisciplinary groups, including all managers, were formed with the aim of identifying criteria for inclusion of patients and suitable instruments for outcome assessment. The inclusion criteria were defined as follows: all patients considered for rehabilitation in any of the participating outpatient rehabilitation centres; with a neurological disease/injury; $\geq 18$ years of age; able to participate in the data collection; and considered for interventions designed to influence any or several of the target outcome areas (balance, movement, activity/participation, health-related quality of life and overall health). Exclusion criteria were as follows: a patient who attended solely for a specific assessment/investigation; palliative interventions; interventions not intended to affect any of the selected outcome areas; or individuals with a rapidly progressing disease. The inclusion and exclusion criteria were identified and selected by consensus during a discussion that included all the participating professionals.

The International Classification of Function, Disability and Health (ICF) was used to identify appropriate target areas [18]. The following instruments, relevant to the target areas for outcome assessment, were included in the data collection template: BDL Balance Scale [19], Berg Balance Scale [20], Swedish Physiotherapy Clinical Outcome Variables (S-COVS) [21], Canadian Occupational Performance Measure (COPM) [22], EuroQoL-5 Dimension (EQ-5D), and EuroQoL-Visual Analogue Scale (EQ-VAS) [23].

The template was supplemented with some general background information (age, diagnosis, and rehabilitation start and end dates). To increase reliability, a manual with instructions on registering data was developed. Systematic data collection began at the beginning of 2010. After 2 years, enough data were collected to begin discussions on various aspects of quality improvement and suggestions for specific studies. Data included only the assessments relevant for evaluation of the interventions chosen for a specific patient (individualized data collection). In other words, all instruments were not used for all patients.

\subsection{Study Participants}

The study participants had all been considered for rehabilitation at one of the five outpatient rehabilitation units within a 2-year period. Participants were assigned consecutively and those who met the following criteria were included: a) diagnosed with stroke, ICD-I64-stroke, not specified as haemorrhage or infarction; or ICD-I69-sequelae of cerebrovascular disease [24]; b) considered for rehabilitation interventions designed to improve balance and/or movement and/or activity/participation, health-related quality of life, and overall health; and c) completed the rehabilitation programme with documented results from assessments before and after rehabilitation. One hundred and ninety-nine patients met the inclusion criteria; 148 were classified as ICD-I64 and 51 as ICD-I69. There was no significant difference between the groups with respect to gender $(\mathrm{p}=0.983)$, age $(\mathrm{p}=$ $0.122)$, or length of the rehabilitation period $(p=0.198)$ (Table 1$)$.

The outcome from one or more of the assessment instruments was available for all participants. Because the rehabilitation goals together with the combination of interventions were planned individually, multi-focal and multi-professional, the instruments used for outcome evaluation varied among the patients. Hence, the number of patients assessed with the different instruments varied (Table 2).

\subsection{Outcome Measure: Validity and Reliability}

The BDL Balance Scale is a standardized instrument used by therapists to evaluate and register a patient's 
Table 1. The study participants.

\begin{tabular}{|c|c|c|c|c|}
\hline \multirow{2}{*}{ Characteristic } & & \multicolumn{2}{|c|}{ Study participants } & \multirow{2}{*}{$\mathrm{p}$ value } \\
\hline & & ICD-I64 $(n=148)$ & ICD-I69 $(n=51)$ & \\
\hline \multirow[t]{3}{*}{ Gender } & Male & $81(54.7 \%)$ & $28(54.9 \%)$ & \multirow{2}{*}{0.983 (ns) } \\
\hline & Female & 67 (45.3\%) & $23(45.1 \%)$ & \\
\hline & Min & 35 & 40 & \\
\hline \multirow[t]{3}{*}{ Age (years) } & Max & 92 & 88 & 0.122 (ns) \\
\hline & Mean (SD) & $72(11.84)$ & $70(10.21)$ & \\
\hline & Min & 2 & 2 & \\
\hline \multirow[t]{2}{*}{ Rehabilitation period (days) } & Max & 419 & 412 & 0.198 (ns) \\
\hline & Mean (SD) & $86(85.74)$ & $92(78.47)$ & \\
\hline
\end{tabular}

Note: The statistical analyses were performed using SPSS, $\chi^{2}$ for gender and the Mann-Whitney U test for age and rehabilitation period. ns, not significant; SD, standard deviation.

Table 2. The number of patients assessed with the different assessment instruments.

\begin{tabular}{cccccccc}
\hline & \multicolumn{7}{c}{ Assessment instrument, n (\%) } \\
\hline & $\begin{array}{c}\text { BDL } \\
\text { (balance) }\end{array}$ & $\begin{array}{c}\text { Berg } \\
\text { (balance) }\end{array}$ & $\begin{array}{c}\text { COPM-S (satisfaction with } \\
\text { performance) }\end{array}$ & $\begin{array}{c}\text { COPM-P (activity } \\
\text { performance) }\end{array}$ & $\begin{array}{c}\text { EQ-5D } \\
\text { (quality of life) }\end{array}$ & $\begin{array}{c}\text { EQ-VAS } \\
\text { (health) }\end{array}$ & $\begin{array}{c}\text { S-COVS } \\
\text { (mobility) }\end{array}$ \\
\hline Number & 23 & 72 & 95 & 97 & 133 & 111 & 37 \\
ICD-I64 & $18(78)$ & $61(85)$ & $74(78)$ & $75(77)$ & $100(75)$ & $89(80)$ & $28(76)$ \\
ICD-I69 & $5(22)$ & $11(15)$ & $21(22)$ & $22(23)$ & $33(25)$ & $22(20)$ & $9(24)$ \\
\hline
\end{tabular}

standing and walking balance. The instrument consists of nine different items concerning different functional tasks such as standing with feet together with eyes open or closed and walking in different ways. The items are assessed according to a 5-point scale $(0-4)$, where " 0 " means inability to perform the task of the item and “ 4 " gives maximum points. The total maximum score in the instrument is 40 points. The BDL has excellent intra-rater reliability (intraclass correlation coefficient $[\mathrm{ICC}] \geq 0.99$ ) and good reliability in repeated measures (test-retest, ICC $\geq 0.96$ ) [19].

Therapists use the Berg Balance Scale to assess the patient's balance, focusing on whether the patient is able to maintain a position while performing a voluntary movement [20] [25]. The Berg Balance scale includes 14-items where the patient is asked to perform different functional tasks. The performance on each task is assessed on a five-point scale, ranging from 0 - 4, " 0 ” indicates the lowest level of function and " 4 " the highest level. Total score $=56$. The instrument has excellent inter-rater reliability (ICC $=0.98)$ [26].

S-COVS, developed for patients with neuromuscular and musculoskeletal impairments, is used to assess movement, walking, wheelchair driving, sitting balance, and arm function. S-COVS consists of 13 items (rolling, transfers, ambulation and arm function), and each task is clinically assessed on a scale from 1 to 7 . The overall score ranges from 13 to 91 . A higher score denotes greater mobility and functional status. The instrument has excellent inter-rater reliability (ICC $=0.97$ ) [21], with an exact match in $>90 \%$ for seven of the 13 variables [27]. The instrument is also used to evaluate patients with neurological diseases/injuries, and Choy et al. [28] found that it has a very high inter-rater (ICC > 0.97) and test-retest reliability ( 1 week ICC > 0.99, 3 months ICC > 0.99).

The COPM is a client-centred instrument in which data are collected through a semi-structured interview. The COPM was designed as an outcome measure to identify perceived changes in occupational performance and satisfaction with that performance over time [22]. The client scores performance in identified problems and satisfaction with that performance on two ten-point scales range from " 1 " meaning "not able to do it at all" or "not satisfied at all” to “10”, meaning "able to do it extremely well” or extremely satisfied”. Clinically, the most important score of the COPM is the change score measuring change between the mean-score at the initial evaluation and the mean-score at reevaluation. The instrument has good sensitivity to change [29]. COPM has been 
evaluated regarding validity and reliability in the assessment of stroke patients, demonstrating good test-retest reliability for performance as well as satisfaction with performance $(r=0.89$ and $r=0.88, p<0.001)$ [30].

EQ-5D is a standardized instrument that focuses on health-related quality of life. The instrument consists of two parts. One part includes a description of five dimensions considered pertinent to perceived quality of life: mobility, self-care, usual activities, pain/discomfort, and anxiety/depression and each dimension has three levels of severity corresponding to 1 = "no problems", 2 = "some problems", and 3 = "extreme problems". This allows the generation of $243\left(3^{5}\right)$ possible combinations, i.e. health states. EQ-5D health states, defined by the EQ-5D descriptive system, may then be converted into a single summary index by applying a formula that essentially attaches values (weights) to each of the levels in each dimension. The index can be calculated by deducting the appropriate weights from 1 , the value for full health. Negative values can be considered to correspond to health states worse than death. The second part consists of a visual analogue scale (EQ-VAS) where the current estimated overall health is marked on a scale from $0=$ "Worst imaginable health state" to $100=$ "Best imaginable health state" [23]. EQ-5D has good test-retest reliability [31]. Results from EQ-5D have been compared with results from the Barthel ADL-Index in a study on patients with stroke, showing moderate validity (ICC $=0.70$ ) [32].

\subsection{Statistics}

All data were analysed using the Statistical Package for the Social Sciences 19 (SPSS). Non-parametric statistical methods were used for comparisons of groups as well as comparisons of before and after data within groups [33]. Statistical comparisons between the diagnostic groups, ICD-I64 versus ICD-I69, were performed using the $\chi^{2}$ test and the Mann-Whitney U test. The Wilcoxon signed rank test was used to analyse the outcome of the rehabilitation interventions within each diagnostic group. The Mann-Whitney $U$ test was also used to compare data between the two diagnostic groups regarding the start and final values and outcomes (the difference between the initial and final assessments). The level of significance was set at $\mathrm{p}<0.05$.

\subsection{Ethical Considerations}

Data were collected as part of the routine rehabilitation. For this study, data were analysed without any identifying information in terms of names or birth numbers. No approval from the local ethic committee was needed because all analyses were performed on existing data and thus no specific study interventions were offered to the study group. The managers of the five units included in the study agreed to and supported the data analyses.

\section{Results}

The results for both diagnostic groups before and after the rehabilitation interventions are shown in Table 3 .

The rehabilitation results (the difference between before and after value) for both groups were compared. Analysis of the rehabilitation outcome for the ICD-I64 group showed an improvement at follow-up $(\mathrm{p}<0.01)$ for all outcome measures. The ICD-I69 group showed an improvement at follow-up for balance (Berg Balance Scale), occupational performance, and satisfaction with performance (COPM) (p $<0.05$, Table 3). Analysis of the results for quality of life and health, as measured with the EQ-5D and EQ-VAS for the ICD-I69 group, showed almost as many patients had a negative outcome at follow-up as a positive outcome (Table 4).

Analysis of the five separate dimensions in EQ-5D was conducted to look closer into the fact that $42.5 \%$ of the patients in the ICD-I69 group rated their health-related quality of life lower after completing rehabilitation than before the interventions started. The highest mean value (on a three-point scale where 3 = worst alternative) for the ICD-I69 group at follow-up was found to be for the usual activities dimension (mean, 1.87). The lowest mean value (1.55) for the same diagnostic group at follow-up was found for the anxiety/depression dimension (Table 5).

The analyses further revealed that the anxiety/depression and mobility dimensions showed the least improvement (mean, 0.26), whereas the usual activities dimension showed the most improvement (mean, 0.55) (Table 5).

The before and after values for the ICD-I64 and ICD-I69 groups were compared with the outcome, the difference between the before and after values. There were no significant differences according to the before or after values except for the Berg Balance Scale, which showed a significant difference in favour of the ICD-I64 group $(p=0.015)$ at the end of the rehabilitation period. A comparison of the outcome (difference between the 
Table 3. Mean value and standard deviation before and after the period of rehabilitation for the ICD-I64 group versus the ICD-I69 group.

\begin{tabular}{|c|c|c|c|c|c|c|c|c|}
\hline \multirow[b]{2}{*}{$\begin{array}{l}\text { Outcome } \\
\text { instrument }\end{array}$} & \multicolumn{4}{|c|}{ ICD-I64 } & \multicolumn{4}{|c|}{ ICD-I69 } \\
\hline & $\begin{array}{c}\text { Before } \\
\text { Mean (SD) }\end{array}$ & $\begin{array}{c}\text { After } \\
\text { Mean (SD) }\end{array}$ & $\mathrm{n}$ & $\begin{array}{c}\text { Difference } \\
\text { p value }\end{array}$ & $\begin{array}{c}\text { Before } \\
\text { Mean (SD) }\end{array}$ & $\begin{array}{c}\text { After } \\
\text { Mean (SD) }\end{array}$ & $\mathrm{n}$ & $\begin{array}{c}\text { Difference } \\
\text { p value }\end{array}$ \\
\hline BDL & 18.06 (8.05) & 26.28 (9.69) & 18 & $<0.001$ & $\begin{array}{l}18.40 \\
(2.61)\end{array}$ & 24.60 (8.08) & 5 & (ns) \\
\hline $\begin{array}{l}\text { Berg balance } \\
\text { scale }\end{array}$ & 42.52 (8.08) & 48.31 (6.68) & 61 & $<0.001$ & $\begin{array}{c}34.91 \\
(14.66)\end{array}$ & $42.73(8.34)$ & 11 & $<0.05$ \\
\hline $\begin{array}{c}\text { COPM } \\
\text { satisfaction }\end{array}$ & 3.17 (1.73) & $5.93(2.28)$ & 74 & $<0.001$ & $3.40(2.07)$ & $6.10(2.38)$ & 21 & $<0.001$ \\
\hline $\begin{array}{c}\text { COPM } \\
\text { performance }\end{array}$ & 3.61 (1.72) & $6.22(2.02)$ & 75 & $<0.001$ & $3.95(2.02)$ & $6.24(1.78)$ & 22 & $<0.001$ \\
\hline EQ-5D & $0.54(0.28)$ & $0.62(0.26)$ & 100 & $<0.01$ & $0.55(0.33)$ & $0.58(0.27)$ & 33 & (ns) \\
\hline EQ-VAS & $54.26(22.02)$ & 64.25 (16.94) & 89 & $<0.001$ & $61.73(16.10)$ & 59.49 (18.95) & 22 & (ns) \\
\hline S-COVS & 52.07 (16.28) & 60.64 (16.39) & 28 & $<0.001$ & $57(20.45)$ & $60.11(19.23)$ & 9 & (ns) \\
\hline
\end{tabular}

Note: Analyses of the differences between the before and after values for each diagnostic group, based on the Wilcoxon signed rank test, $\mathrm{p}<0.05$. ns, not significant.

Table 4. The direction of change after rehabilitation for all assessment instruments.

\begin{tabular}{|c|c|c|c|c|c|c|}
\hline \multirow[b]{2}{*}{ Outcome instruments } & \multicolumn{3}{|c|}{ ICD-I64 } & \multicolumn{3}{|c|}{ ICD-I69 } \\
\hline & $\begin{array}{c}\text { Positive } \\
\text { results (\%) }\end{array}$ & $\begin{array}{c}\text { Negative } \\
\text { results (\%) }\end{array}$ & $\begin{array}{l}\text { Ties } \\
(\%)\end{array}$ & $\begin{array}{c}\text { Positive } \\
\text { results (\%) }\end{array}$ & $\begin{array}{l}\text { Negative } \\
\text { results (\%) }\end{array}$ & $\begin{array}{l}\text { Ties } \\
\text { (\%) }\end{array}$ \\
\hline BDL & 89 & 0 & 11 & 60 & 20 & 20 \\
\hline Bergs balance scale & 90 & 3 & 7 & 73 & 9 & 18 \\
\hline COPM satisfaction & 89 & 7 & 4 & 76 & 5 & 19 \\
\hline COPM performance & 87 & 6.5 & 6.5 & 86 & 5 & 9 \\
\hline EQ-5D index & 53 & 25 & 22 & 45.5 & 42.5 & 12 \\
\hline EQ-VAS & 65 & 22 & 12 & 45 & 41 & 14 \\
\hline S-COVS & 93 & 3.5 & 3.5 & 67 & 22 & 11 \\
\hline
\end{tabular}

Table 5. Means for the ICD-I69 group for the five different dimensions in EQ-5D relating to the values $(1-3)$ at reassessment and the difference = outcome.

\begin{tabular}{cccccc}
\hline & Mobility & Self-care & $\begin{array}{c}\text { EQ-5D dimension } \\
\text { activities }\end{array}$ & $\begin{array}{c}\text { Pain/ } \\
\text { discomfort }\end{array}$ \\
\cline { 2 - 5 } Anxiety/ \\
depression
\end{tabular}

initial and final data) showed a significant difference between the groups for mobility as measured by S-COVS ( $p=0.03$ ); the ICD-I64 group showed more improvement. However, there were no other significant differences between the groups according to the outcome results (Table 3 ).

\section{Summary of Results, Their Use and Implementation}

All outcome variables were positively affected in the early rehabilitation intervention group (ICD-I64). For patients undergoing rehabilitation (ICD-I69) more than 1 year after their stroke, the effects were positive for balance (Berg Balance Scale) and for occupational performance and satisfaction with performance (COPM). No difference was seen for the ICD-I69 group in items related to quality of life (EQ-5D), health (EQ-VAS) and 
mobility (S-COVS). The difference in outcome between the groups was only significant for mobility (S-COVS), where the ICD-I64 group showed more improvement. The results from the study were presented at a meeting for all personnel who had participated in building up the template for outcome measures; discussions and reflections were encouraged. The managers then presented a need for a more specific study on the quality of life for patients with stroke, with a special focus on anxiety and depression based on the results presented (Table 5). Two occupational therapists within the organization were commissioned to undertake focus-group interviews to gather more information on this subject. The results from these interviews will be presented elsewhere. After highlighting the lack of improvement in patients with anxiety and depression, this became a focus for further discussions on the approach and focus for measures as well as quality improvement.

\section{Discussion}

Healthcare resources are not infinite; at the same time, the need for rehabilitation will increase as medical treatments develop and life expectancy increases. In addition, today's patients have access to more knowledge about the most effective care and rehabilitation practices; they are expected to have an active role in discussions and decisions, placing further demands on health care professionals. Furthermore, taxpayers and policymakers expect health care professionals to rely on evidence to determine the best available treatment. In neurological rehabilitation, where it is not possible to have a standard rehabilitation programme that fits all, it is important to keep EBP at the forefront of discussions and to carefully monitor and evaluate the interventions carried out; such diligence will provide the basis for further discussions on effective rehabilitation practices. Finlayson [34], for example, points out that it is important to identify the needs of broader groups of patients in order to develop or modify services, programmes, policies and goals. To this end, this study shows how systematic collection of clinical data could help provide the basis for discussions on evidence with respect to stroke rehabilitation. The main objective was to describe the development of a specific data template designed to support therapists within outpatient neurology rehabilitation to improve the quality of rehabilitation by following up and discussing outcomes.

Therapists generally have a positive attitude regarding the use of evidence in clinical practice. However, the main barriers to EBP have been identified as insufficient facilities and lack of time [35]. The biggest challenge in the development of the template was to come up with a joint decision on which evaluation instruments should be included in the template, that is, the functions and skills that would constitute end points. We believe that the key factor for success was to let all professionals, including the managers at each unit, meet and make proposals until a final decision was reached. By using the ICF model as a starting point, we managed to come to a conclusion and have a proposal for the template at the end of the second meeting. By letting all personnel participate in the process, the implementation of the template was already started. A member of each rehabilitation unit was included in the organising group, which also facilitated implementation and organization of the data collection at each unit.

It was a challenge to assess such a large amount of data from several, although similar, clinical settings and from a variety of professionals and a variety of patients with different physical and cognitive prerequisites.

The results of this study support the idea of developing clinically specific and relevant follow-up structures for outcome evaluation as a basis for improving rehabilitation programmes. It was a challenge to assess such a large amount of data from several different, although similar, clinical settings and from a variety of professionals and a variety of patients with different physical and cognitive prerequisites. The extent of this study might be considered as a limitation because it increases the risk of reliability errors based on the different data collectors and professions. However, the fact remains that the study reflects clinical reality, presenting both challenges and opportunities. It was a significant challenge to decide how to process and interpret the clinical data originating from individually tailored interventions, measures, and treatment periods. However, a client-centred perspective was established from the beginning of the study and considered during the analysis; the varied rehabilitation strategies were evaluated using an individualized mixture of assessment tools so that only those instruments measuring aspects related to the goal(s) of each patient were used to evaluate outcomes. When a patient identifies and prioritizes the difficulties with occupational performance, that patient becomes more motivated, engaged and involved in the rehabilitation process overall, and this is especially evident when patients formulate their own rehabilitation goals [36]-[38].

The health care professionals and managers were very interested in the fact that although occupational performance and satisfaction with the performance during rehabilitation significantly improved among ICD-I69 pa- 
tients, many of these patients rated a decrease in health-related quality of life and estimated health when the rehabilitation period ended (Table 4). In the ICD-I69 group, almost as many patients indicated a decrease as an increase in health-related quality of life and health experience. In the ICD-I64 group, however, 53\% - 65\% of the patients indicated improved health-related quality of life and self-rated health experience and only about $25 \%$ of the patients showed a negative result. The relatively high incidence of depression in patients with stroke is well known, and the prevalence of depression among stroke patients admitted to a hospital ward is estimated to be $19.3 \%$ and as much as $23.3 \%$ for patients in outpatient care [39]. This result raises important and clinically relevant questions. Why did the patients in the ICD-I69 group feel worse when their rehabilitation ended? Do the health care professionals need to consider and address this more during the rehabilitation period? Systematic data collection might help improve knowledge and highlight important aspects of stroke rehabilitation that might be difficult to see in the busy milieu of everyday clinical practice.

In addition, the health care professionals who participated in this study found it interesting that the outcome from rehabilitation of patients who were newly diagnosed with stroke (ICD-I64) was similar to the outcome from rehabilitation in patients who received an additional period of rehabilitation more than 1 year after onset of stroke (ICD-I69). Patients who have had a stroke are a heterogeneous group as previously mentioned, with different physical and cognitive prerequisites and different goals for treatment. Table 3 acknowledges these differences through the large standard deviation within almost all instruments at the start of the rehabilitation period. In addition, the wide ranges of rehabilitation periods illustrate this heterogeneity further (Table 1). The data from this systematic data collection process confirmed that the different mixes of interventions used by the clinicians have a positive effect on patients' estimated occupational performance and satisfaction with performance. This is considered to be the main outcome variable in client-centred rehabilitation and is thus an important outcome showing that the chosen mix of interventions had an evident effect. In addition, results illustrate that the group of patients undergoing rehabilitation more than a year after their stroke (ICD-I69) still had the potential to improve their occupational performance and satisfaction with that performance. This finding was not entirely surprising based on clinical experience, but it was very valuable for the health care providers to be able to confirm this and for future discussion on effectiveness and efficiency. Sudsawad [40] concluded that clinical experience is as import ant to discussions about EBP as research evidence. Thus, it is of great value to be able to look at the clinical experience in a systematic way and to reflect on relevant research in the light of the evidence derived from the local setting. Collecting clinical evidence and looking at it in the light of different research results should help clinicians to develop their clinic in a conscientious way. According to Taylor [4], EBP should use evidence to substantiate the clinical decision-making process. Clearly, systematic data collection within clinics provides access to information on clinical outcomes from several different sources that can be used to support decisions. The results also demonstrate the importance of the opportunity to discuss and reflect on which patients will gain the most benefit from rehabilitation interventions and what might be further studied before decision making. Before the results of the study were presented, patients in the ICD-I69 group had not been prioritized by the five rehabilitation units. After discussing the results, these patients were given a higher priority.

This study was not possible with the data available in the existing Quality Registers. The opportunity was given to all employees within outpatient neurorehabilitation organizations to influence which outcome measures should be used in the data collection. Shared data collection decided on by therapists and anchored in management provided the platform for discussions on quality and improvement within the local clinics.

Several challenges exist and one barrier to building up and implementing evidence-based rehabilitation has been found to be in sufficient interdisciplinary collaboration [11]. This problem has mainly been overcome in the collaboration described in this study. The managers as well as other health care professionals who participated in this study found that the data collection process encouraged them to ask questions about the effectiveness of their treatment strategies. In a review on research use and EBP in occupational therapy, Thomas and Law [41] suggested that creating opportunities for clinicians to engage in research as a part of their professional responsibilities might be a useful strategy for enhancing EBP. According to Walker et al. [42], because transferring research evidence into practice is a challenge, clinicians, researchers, patients, and policymakers need to work together to bring about change. The findings in the present study were easy for all the employees to assimilate. This systematic data collection shows how clinicians can become closely involved in clinical research while collecting data, and this understanding can be used to help ensure that the needs of patients are more thoroughly and individually addressed while also highlighting the importance of including policymakers and managers in treatment discussions. 
This systematic data collection study brought employees and managers together as well as the different units working with stroke patients; these relationships increase the value of our results, and emphasize the value of discussions with respect to making priorities transparent. Such an approach will benefit the patients.

\section{Study Limitations and Strengths}

Some limitations should be noted. Different employees collected and documented the results, which might have an impact on the reliability of the results. However, the same therapist who did the initial assessments also did the follow-up evaluations and registration, which is important to improve reliability. Another limitation is related to the amount of missing data, especially data from follow-ups. We do not know why data were missing and thus we do not know if those patients were different from those who completed the template. In addition, differences in the type of interventions as well as rehabilitation periods could be considered a weakness in the study. However, these differences could also be considered as a strength, depending on how the concept of client-centeredness is understood and used. When comparing the different diagnostic groups (ICD-I64 and ICDI69), we found that the groups did not differ with respect to gender, age, and duration of the treatment period.

When planning the template for follow-up, we strived for reliable and valid outcome assessment tools. All the instruments used are considered sufficiently valid and reliable as outcome tools. This is considered a strength of the study.

\section{Conclusion}

With support from managers and employees, a database was developed that was expected to be useful in providing answers to and information on clinically relevant and interesting questions and discussions. Systematic data collection can serve to build up clinical evidence in a clinical setting and enhance EBP.

\section{Acknowledgements}

This study was supported by grants from the County Council of Östergötland.

\section{Declaration of Interest}

The authors report no conflicts of interest. The authors alone are responsible for the content and writing of the paper.

\section{References}

[1] Sackett, D.L., Rosenberg, W.M.C., Gray, J.A.M. and Richardson, W.S. (1996) Evidence Based Medicine: What It Is and What It Isn't. BMJ, 312, 71-72. http://dx.doi.org/10.1136/bmj.312.7023.71

[2] Law, M. and MacDermid, J. (2008) Evidence-Based Rehabilitation. A Guide to Practice. SLACK, Thorofare, NJ.

[3] French, P. (1999) The Development of Evidence-Based Nursing. Journal of Advanced Nursing, 29, 72-78. http://dx.doi.org/10.1046/j.1365-2648.1999.00865.x

[4] Taylor, C. (2007) Evidence-Based Practice for Occupational Therapists. Blackwell, Malden, MA.

[5] Eso-Stroke.org (2015) Stroke Facts. http://www.eso-stroke.org/eso-stroke/strokeinformation/stroke-facts.html

[6] Riksstroke.org (2014) Årsrapport 2013. http://www.riksstroke.org/wp-content/uploads/2014/07/Strokerapport_AKUTTIA3man_LR.pdf

[7] Ghatnekar, O. (2013) The Burden of Stroke in Sweden-Studies on Costs and Quality of Life Based on Riks-Stroke, the Swedish Stroke Register. PhD Dissertation, Department of Public Health and Clinical Medicine, Umeå.

[8] Mayo, N.E., Wood-Dauphinee, S., Coté, R., Durcan, L. and Carlton, J. (2002) Activity, Participation, and Quality of Life 6 Months Poststroke. Archives of Physical Medicine and Rehabilitation, 83, 1035-1042. http://dx.doi.org/10.1053/apmr.2002.33984

[9] Hartman-Maeir, A., Soroker, N., Ring, H., Avni, N. and Katz, N. (2006) Activities, Participation and Satisfaction One-Year Post Stroke. Disability \& Rehabilitation, 29, 559-566. http://dx.doi.org/10.1080/09638280600924996

[10] Stroke Unit Trialists' Collaboration (2007) Organised Inpatient (Stroke Unit) Care for Stroke. Cochrane Database of Systematic Reviews, 4, Article ID: CD000197. http://dx.doi.org/10.1002/14651858.cd000197.pub2

[11] Bayley, M., Hurdowarz, A., Richards, C., Korner-Bitensky, N., Wood-Dauphinee, S., Eng, J., McKay-Lyons, M., Har- 
rison, E., Teasell, R., Harrison, M. and Graham, I.D. (2012) Barriers to Implementation of Stroke Rehabilitation Evidence: Findings from a Multi-Site Pilot Project. Disability \& Rehabilitation, 34, 1633-1638. http://dx.doi.org/10.3109/09638288.2012.656790

[12] McIntyre, A., Richardson, M., Janzen, S., Hussein, N. and Teasell, R. (2014) The Evolution of Stroke Rehabilitation Randomized Controlled Trials. International Journal of Stroke, 9, 789-792. http://dx.doi.org/10.1111/ijs.12272

[13] Socialstyrelsen (2010) Nationella RIKTLINJER för strokesjukvård 2009—Stöd för Styrning och Ledning. Socialstyrelsen, Västerås.

[14] Tickle-Degnen, L. and Bedell, G. (2003) Heterarchy and Hierarchy: A Critical Appraisal of the "Levels of Evidence" as a Tool for Clinical Decision Making. American Journal of Occupational Therapy, 57, 234-237. http://dx.doi.org/10.5014/ajot.57.2.234

[15] Rösblad, B. (2014) Kartläggning av Nationella Kvalitetsregister ur ett fysioterapeutiskt perspektiv: En förstudie. (In Swedish) http://www.fysioterapeuterna.se/Global/Nyheter dokument/Nationella\%20Kvalitetsregister \%20En\%20kartl\%C3\%A4 ggning\%20ur\%20ett\%20fysioterapeutiskat\%20perspektiv.pdf

[16] Rosén, M. (2010) Guldgruvan i Hälso-och Sjukvården. Ljungbergs Tryckeri, Stockholm.

[17] Sunnerhagen, K.S., Flansbjer, U.-B., Lannsjö, M., Tölli, A. and Lundgren-Nilsson, Å. (2014) WebRehab: A Swedish Database for Quality Control in Rehabilitation. Journal of Rehabilitation Medicine, 46, 958-962. http://dx.doi.org/10.2340/16501977-1886

[18] World Health Organization (2001) International Classification of Functioning, Disability and Health: ICF. WHO, Geneva.

[19] Lindmark, B., Liljenäs, Å. and Hellström, L. (2012) Assessment of Minor or Moderate Balance: A Reliability Study and Comparison with Healthy Subjects. Advances in Physiotherapy, 14, 3-9. http://dx.doi.org/10.3109/14038196.2011.640350

[20] Berg, K., Wood-Dauphinée, S., Williams, J.I. and Gayton, D. (1989) Measuring Balance in the Elderly: Preliminary Development of an Instrument. Physiotherapy Canada, 4, 304-311. http://dx.doi.org/10.3138/ptc.41.6.304

[21] Hasselgren-Nyberg, L., Omgren, M., Nyberg, L. and Gustafson, Y. (1997) S-COVS. Den svenska versionen av Physiotherapy Clinical Outcome Variables Scale. Nordisk Fysioterapi, 1, 109-113.

[22] Law, M., Baptiste, S., Carswell, A., McColl, M.A., Polatajko, H. and Pollock, N. (2005) Canadian Occupational Performance Measure. Canadian Association of Occupational Therapists, Ottawa.

[23] Rabin, R., Oemar, M. and Oppe, M. (2011) EQ-5D-3L User Guide-Basic Information on How to Use the EQ-5D-3L Instrument. http://euroqol.org

[24] World Health Organization (1990) International Classification of Diseases (ICD). WHO, Geneva.

[25] Lundin-Olson, L., Jensen, J. and Waling, K. (1996) The Swedish Version of the Berg Balance Scale. Sjukgymnasten: Vetenskapligt Supplement, 1, 6-9. (In Swedish)

[26] Lundin-Olsson, L., Lindmark, B., Nillbrand, A. and Gustafson, Y. (1998) Bergs Balansskala: Prövning av Interbedömarreliabilitet. Nordisk Fysioterapi, 2, 3-8.

[27] Seaby, L. and Torrance, G. (1989) Reliability of a Physiotherapy Functional Assessment Used in a Rehabilitation Setting. Physiotherapy Canada, 41, 264-271.

[28] Choy, N.L., Kuys, S., Richards, M. and Isles, R. (2002) Measurement of Functional Ability Following Traumatic Brain Injury Using the Clinical Outcomes Variable Scale: A Reliability Study. Australian Journal of Physiotherapy, 48, 3539. http://dx.doi.org/10.1016/S0004-9514(14)60280-4

[29] Wressle, E., Samuelsson, K. and Henriksson, C. (1999) Responsiveness of the Swedish Version of the Canadian Occupational Performance Measure. Scandinavian Journal of Occupational Therapy, 6, 84-89. http://dx.doi.org/10.1080/110381299443771

[30] Cup, E., Scholte op Reimer, W., Thijssen, M. and van Kuyk-Minis, M. (2003) Reliability and Validity of the Canadian Occupational Performance Measure in Stroke Patients. Clinical Rehabilitation, 17, 402-409. http://dx.doi.org/10.1191/0269215503cr635oa

[31] van Agtm, H.M.E., Essik-Bot, M.-L., Krabbe, P.F.M. and Bonsel, G.J. (1994) Test-Retest Reliability of Health State Valuations Collected with the EuroQol Questionnaire. Social Science \& Medicine, 39, 1537-1544. http://dx.doi.org/10.1016/0277-9536(94)90005-1

[32] van Exel, N.J.A., Scholte op Reimer, W.J.M. and Koopmanschap, M.A. (2004) Assessment of Post-Stroke Quality of Life in Cost-Effectiveness Studies: The Usefulness of the Barthel Index and the EuroQol-5D. Quality of Life Research, 13, 427-433. http://dx.doi.org/10.1023/B:QURE.0000018496.02968.50

[33] Altman, D.G. (1999) Practical Statistics for Medical Research. Chapman \& Hall, London. 
[34] Finlayson, M. (2006) Assessing the Need for Services. In: Kielhofner, G., Ed., Research in Occupational TherapyMethods of Inquiry for Enhancing Practice, F.A Davis, Philadelphia, 591-606.

[35] Samuelsson, K. and Wressle, E. (2015) Turning Evidence into Practice: Barriers to Research Use among Occupational Therapists. British Journal of Occupational Therapy, 78, 175-181. http://dx.doi.org/10.1177/0308022615569511

[36] Larsson Lund, M. (2004) Living with Physical Disability. Experiences of the Rehabilitation Process, Occupations and Participation in Everyday Life. PhD Dissertation, Umeå University, Umeå.

[37] Wressle, E. (2002) Client Participation in the Rehabilitation Process. PhD Dissertation, Linköping University, Linköping.

[38] Wressle, E., Lindstrand, J., Neher, M., Marcusson, J. and Henriksson, C. (2003) Occupational Performance Measure as an Outcome Measure and Team Tool in a Day Treatment Program. Disability \& Rehabilitation, 25, 497-506. http://dx.doi.org/10.1080/0963828031000090560

[39] Robinson, R.G. (2003) Poststroke Depression: Prevalence, Diagnosis, Treatment and Disease Progression. Biological Psychiatry, 54, 376-387. http://dx.doi.org/10.1016/S0006-3223(03)00423-2

[40] Sudsawad, P. (2006) Definition, Evolution, and Implementation of Evidence-Based Practice in Occupational Therapy. In: Kielhofner, G., Ed., Research in Occupational Therapy-Methods of Inquiry for Enhancing Practice, F.A Davis, Philadelphia, 656-662.

[41] Thomas, A. and Law, M. (2013) Research Utilization and Evidence-Based Practice in Occupational Therapy: A Scoping Study. American Journal of Occupational Therapy, 67, 55-65. http://dx.doi.org/10.5014/ajot.2013.006395

[42] Walker, M.F., Fisher, R.J., Korner-Bitensky, N., McCluskey, A. and Carey, L.M. (2013) From What We Know to What We Do: Translating Stroke Rehabilitation Research into Practice. International Journal of Stroke, 8, 11-17. http://dx.doi.org/10.1111/j.1747-4949.2012.00974.x 


\section{List of Abbreviations in Alphabetical Order}

BDL The BDL Balance Scale

COPM Canadian Occupational Performance Measure

EQ-5D EuroQoL-5 Dimension

EQ-VAS EuroQoL-Visual Analogue Scale

EBM Evidence based medicine

EBP Evidence-based practice

ICD-I64 Stroke, not specified as haemorrhage or infarction

ICD-I69 Sequelae of cerebrovascular disease

ICF The International Classification of Function, Disability and Health

SALAR Swedish Association of Local Authorities and Regions

S-COVS Swedish Physiotherapy Clinical Outcome Variables

SPSS The Statistical Package for the Social Sciences 19 